

\title{
Adsorption Desorption of Chromium (III) Ion on Cellulose from Wood Powder
}

\author{
Risfidian Mohadi, Nurlisa Hidayati, Aldes Lesbani \\ Department of Chemistry, Faculty of Mathematic and Natural Sciences, Sriwijaya University - Indonesia \\ Corresponding Author: aldeslesbani@yahoo.com; risfidian.mohadi@unsri.ac.id
}

\begin{abstract}
This study of adsorption desorption of chromium ion on cellulose from wood powder has been carried out systematically and also wood powder was used as adsorbent control in this research. Adsorption process was studied through investigation of adsorption time and variation of chromium ion in the adsorption. Desorption process was investigated using several desorption reagents such as hydrochloric acid, ammonium acetate, sodium EDTA, and water. Data of adsorption time of chromium ion on cellulose and wood powder was calculated to obtain adsorption rate constant of chromium ion. Then the data of variation concentration of chromium was formulated to obtain adsorption capacity of chromium ion on cellulose and wood powder. The results showed that adsorption rate constant of chromium on cellulose is $0.007 \mathrm{~min}^{-1}$ and $0.002 \mathrm{~min}^{-1}$ for wood powder. Adsorption capacity of chromium ion on cellulose is higher than on wood powder while $76.92 \mathrm{~mol} / \mathrm{g}$ for cellulose and $55.56 \mathrm{~mol} / \mathrm{g}$ for wood powder. The results of desorption using various desorption shows sodium EDTA is appropriate reagent for desorption of chromium ion on both cellulose and wood powder.
\end{abstract}

Keywords - adsorption, cellulose, chromium, desorption.

Submission: March 26, 2014

Doi: $10.12777 / \mathrm{ijse} \cdot 7 \cdot 1.77-80$

Correction: April 4, 2014

Accepted: July 8, 2014

[How to cite this article: Mohadi, R., Hidayati, N., Lesbani, A. 2014. Adsorption Desorption of Chromium (III) Ion on Cellulose from Wood Powder, International Journal of Science and Engineering, 7(1),77-80. Doi: 10.12777/ijse.7.1.77-80]

\section{Introduction}

Chromium is one of the potential heavy metal as pollutant in the environment. Chromium is produced from various sources including naturally available in earth as chromite ore, $\mathrm{FeCr}_{2} \mathrm{O}_{4}$ and also from human activity in industry [1]. Chromium is also found as metal ion in the sea, river, and lake with small concentration. Chromium has several oxidation numbers from low oxidation number to high oxidation number resulted diversity compound of chromium. This fact makes chromium a little bit different with several block d metal in the first row transition [2]. On the other hand, the toxicity of chromium is high compare with first row transition metal. Thus treatment of chromium should be carried out systematically in order to avoid the toxicity to human.

Several methods for treatment of metal ion from solution have been chemically conducted such as precipitation, adsorption, and ion exchange [3]. Adsorption has advantages than chemical treatment due to simple process, fast, low cost, and no toxicity effect to human [4]. Zero toxicity effect from adsorption to treat metal ion from solution because adsorption use adsorbent in their process. Adsorbent can be classified as organic adsorbent, inorganic adsorbent, and hybrid adsorbent [5], which has advantages and disadvantages depending on situation, equipment, and laboratory environment. Organic adsorbent is interesting to use for heavy metal ion handing because this material is naturally available and renewable. Lesbani et al. [6] reported organic adsorbent such as chitin and chitosan is excellent material for binding metal ion. The process of chitin and chitosan adsorb metal ion is chemical bonding between active site from chitin and chitosan, which we know well as amide and amine functional groups bind to metal ion. Furthermore, Lesbani \& Yusuf [7] also reported organic adsorbent such as natural peat soil is potential adsorbent for metal ion. Peat soil contains several active fractions such as humin [8], humic, and fulvic that can act as natural ligand to make complex formation with metal ion [9]. We report in this research the use of wood powder which contains cellulose as organic adsorbent for chromium ion. Wood powder is renewable, abundant, and inexpensive organic material that can adsorb metal ion [10]. Cellulose from wood powder with hydroxyl group can donate lone pair electron to bind with acceptor electron such as chromium ion [11]. This concept is suitable for heavy metal ion treatment especially for extraction metal ion industry that produces metal for various applications. 


\section{Materials and Methods}

\section{A. Materials and Equipment}

Chemicals were used directly after purchased from Merck without further treatment such as chromium trichloride, hydrochloric acid, sodium EDTA, and ammonium acetate, methanol. Water is purified using ion exchange resin before use. The main instrumentation for this research are atomic absorption spectrophotometer Perkin Elmer 3110 with hallow cathode lamp of chromium, X-ray powder diffraction Shimadzu Lab X Type 6000, and FT-IR spectrophotometer Shimadzu 8201PC.

\section{B. Wood Powder Sampling}

Wood powder was obtained from furniture industry in Palembang, South Sumatera, Indonesia. The woods are mixture of Shorea pinanga "Meranti merah" (Indonesian) and Hopea pierrei "Merawan" (Indonesian). Wood powder was grinded and passes through $100 \mathrm{~mm}$ sieve.

\section{Separation of cellulose from wood powder}

Wood powder pass through $100 \mathrm{~mm}$ sieve was placed into $500 \mathrm{~mL}$ maceration bottle. Methanol was added until half of bottle. The methanol was replaced for 2 days with fresh methanol and the process repeated until colorless of solution. The wood then washed with $5 \%$ hydrochloric acid until neutral $\mathrm{pH}$ for 3 hours using magnetic stirring. Thus crude cellulose was obtained. Characterization of cellulose is carried out using X-Ray diffractometer and FTIR spectroscopy. The IR spectrum was compared with IR spectrum of cellulose standard.

\section{Effect of reaction time for adsorption of chromium} ion into cellulose and wood powder

Cellulose $(0.1 \mathrm{~g})$ was interacted with $10 \mathrm{~mL}$ of chromium ion with concentration $100 \mathrm{mg} / \mathrm{L}$ using batch shaker system. The interaction time for adsorption is 5 , $10,15,20,30,60,120$, and 180 minutes then filtrated. The filtrate was analyzed using atomic absorption spectrophotometer. Similar procedures are repeated by changing cellulose as adsorbent to wood powder as control of adsorption.

\section{E. Adsorption of chromium ion into cellulose and wood powder in various chromium ion concentration}

Cellulose $(0.1 \mathrm{~g})$ was interacted with $10 \mathrm{~mL}$ of chromium ion using batch shaker system at room temperature for 60 minutes. Variation of concentration of chromium ion is $2,5,10,20,50,100$, and $200 \mathrm{mg} / \mathrm{L}$. Filtrate after shaker was analyzed using atomic absorption spectrophotometer. The procedure above was carried out also for wood powder in similar condition with cellulose.

\section{F. Desorption of chromium ion after adsorption into cellulose and wood powder}

Cellulose (1 g) was interacted with chromium ion in $100 \mathrm{mg} / \mathrm{L}$ for $10 \mathrm{~mL}$. The mixture was shaked for 60 minutes to obtain residue and filtrate. Filtrate was analyzed using atomic absorption spectrophotometer. Residue was dried at room temperature and the solid material was divided into 4 parts with $0.2 \mathrm{~g}$ in each part. Desorption process was carried out by adding $10 \mathrm{~mL}$ of hydrochloric acid $0.1 \mathrm{M}$, Sodium EDTA $0.1 \mathrm{M}$, ammonium acetate $0.1 \mathrm{M}$ and water into each solid material, respectively. The mixture is shaked for 60 minutes to obtain filtrate and residue. Filtrate was analyzed using atomic absorption spectrophotometer to obtain the concentration of chromium, which lost from solid material.

\section{Results and Discussions}

The separation of cellulose from wood powder was carried out in two steps i.e. separation of secondary metabolites and primary metabolites except cellulose using methanol followed by hydrochloric acid. The cellulose was characterized using X-ray diffractometer. The XRD pattern of cellulose standard and cellulose from wood powder are show in Fig. 1.

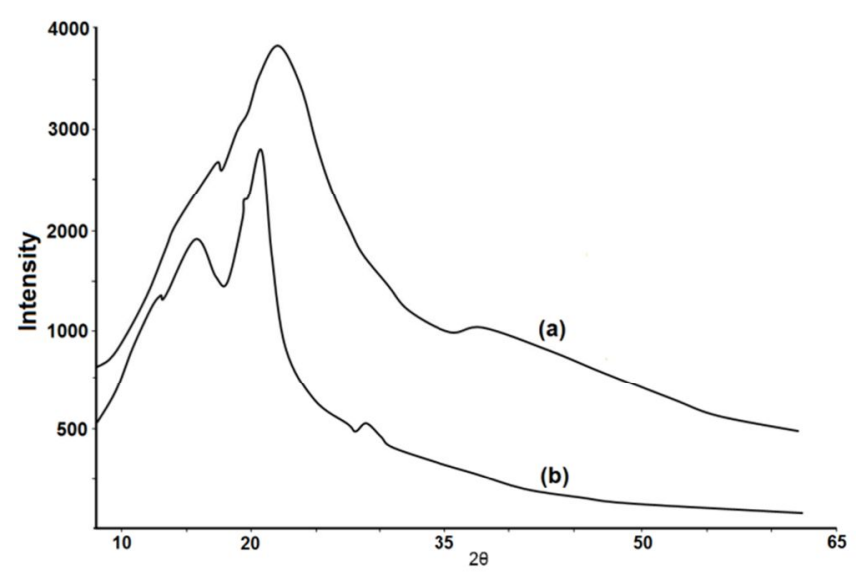

Fig. 1. XRD powder pattern of (a) cellulose standard and (b) cellulose from wood powder.



Fig. 2. FTIR spectra of cellulose (a) cellulose standard and (b) cellulose from wood powder.

XRD powder pattern as shown in Fig. 1 has board patten from 3-60 deg. According to JCPDS file, this pattern is classified as amorphous cellulose. Although the crystallinity of cellulose from wood powder is a little low but separation process of wood powder into cellulose is successful because the XRD pattern in Fig. 1 is similar with XRD pattern of cellulose amorphous [12].

Although cellulose from wood powder has amorphous structure but this material can be used as adsorbent of metal ion, thus the next characterization is identification of functional group using FTIR spectroscopy. An FTIR spectrum of cellulose from wood powder is presented in 
Fig. 2. This spectrum is compared with IR spectrum of standard cellulose from commercial source.

Cellulose from wood powder is quite similar with cellulose standard according to FTIR spectrum as shown in Fig. 2. Hydroxyl and methylene functional groups that are main functional groups in cellulose appeared in FTIR spectrum in Fig. 2. Wavenumbers at $3400 \mathrm{~cm}^{-1}$ and 2900 $\mathrm{cm}^{-1}$ are vibration of hydroxyl and methylene in cellulose, respectively [13]. Therefore, cellulose can be separated from wood powder with simple way and can

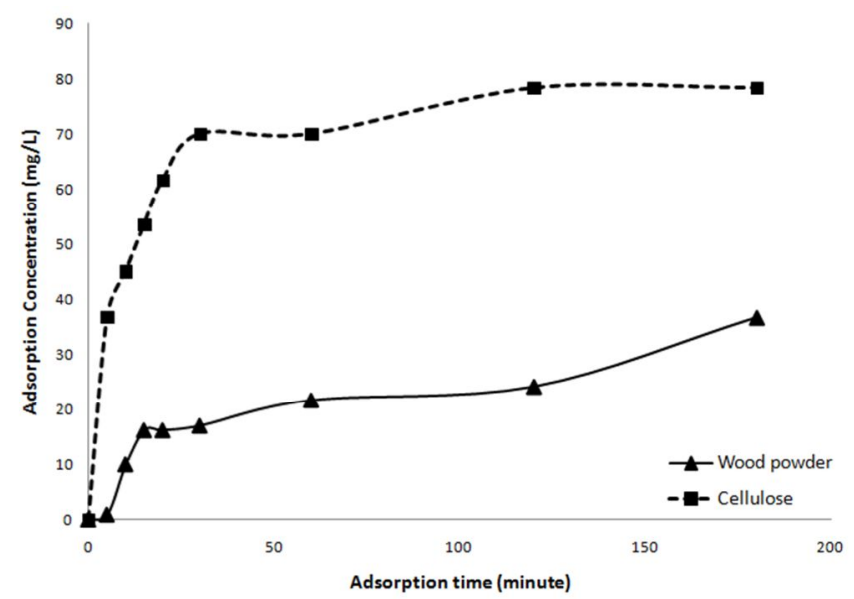

Fig. 3. Effect of time adsorption of chromium ion on cellulose and wood powder.

There is a significant different between time adsorption of chromium ion into cellulose and wood powder. The increasing reaction time for adsorption of chromium ion resulted increase amount of chromium ion adsorp onto cellulose and wood powder. Time adsorption before $50 \mathrm{~min}$ is looks so fast and quite stable to reach equilibrium after $50 \mathrm{~min}$. This data is used to obtain rate adsorption constant by application of Langmuir-Heinselwood equation [14]. The rate adsorption constant of chromium ion into cellulose and wood powder is shown in Table 1 . The data in Table 1 also show the adsorption capacity of chromium ion into cellulose is bigger than onto wood powder. The homogeneity of active site in the cellulose might be an important role to increase the adsorption capacity of chromium ion into cellulose.

The rate adsorption constant of chromium ion into cellulose is faster than into wood powder. Cellulose as adsorbent is more reactive than wood powder in the order to adsorb chromium ion. This kinetic data is also similar with adsorption data at various concentrations of chromium ion as shown in Fig. 4. Although the data in Fig. 4 is thermodynamic data but the phenomena are agree with kinetic data.

Table 1. Adsorption rate constant and adsorption capacity of chromium ion on cellulose and wood powder

\begin{tabular}{|l|l|c|c|}
\hline No. & Adsorbent & $\begin{array}{c}\text { Adsorption rate } \\
\text { constant }\left(\mathrm{min}^{-1}\right)^{*}\end{array}$ & $\begin{array}{c}\text { Adsorption } \\
\text { capacity } \\
\text { (mol/g)\# }\end{array}$ \\
\hline 1 & Wood powder & 0.002 & 55.56 \\
2 & Cellulose & 0.007 & 76.92 \\
\hline
\end{tabular}

* Calculated using Langmuir-Heinselwood equation

* Calculated using Langmuir equation be used as adsorbent. Wood powder is used a control for adsorption in order to study the adsorption properties of chromium ion in this research.

The adsorption of chromium ion is studied by measuring effect of time adsorption and concentration of chromium ion using cellulose and wood powder. The influence of time adsorption is carried out in various time starts from $5 \mathrm{~min}$ until $180 \mathrm{~min}$. The data of adsorption is shown in Fig. 3.

The data in Fig. 4 shows the increasing concentration of chromium ion can increase the amount of chromium ion adsorp into both adsorbents. The adsorption is stable at the concentration $75 \mathrm{mg} / \mathrm{L}$ chromium ion until 100 $\mathrm{mg} / \mathrm{L}$ then increase sharply after $100 \mathrm{mg} / \mathrm{L}$ chromium ion. The adsorption pattern in Fig. 4 indicated the type of physical adsorption. In the other hand, generally the adsorption of metal ion into solid materials is appropriate with Langmuir type adsorption with single layer and chemical adsorption type. In this research, we used data variation concentration of chromium ion in Fig.4 until concentration $100 \mathrm{mg} / \mathrm{L}$ to obtain the thermodynamic data. The adsorption capacity of chromium ion onto cellulose and wood powder can be estimated using Langmuir equation [15] and the data is shown in Fig. 2.

Wood powder contains several site actives such as hydroxyl, amine, amide, and oxygen methylene, which can act as donor electron or ligand in the adsorption [16]. Thus competition of active sites can decrease the capacity of wood powder to adsorp chromium ion. The chromium ion bind to cellulose and wood powder can be studied by desorption process after adsorption using cellulose and wood powder at the reaction time and concentration of chromium ion as show in Fig.3 and 4. Several reagents such as water, hydrochloric acid, ammonium acetate, and sodium ethylene diamine tetraacetate (Na-EDTA) can be used systematically to desorp chromium ion from cellulose and wood powder [17]. The data of desorption process in wood powder and cellulose is shown in Fig. $5 a$ and $5 b$, respectively.

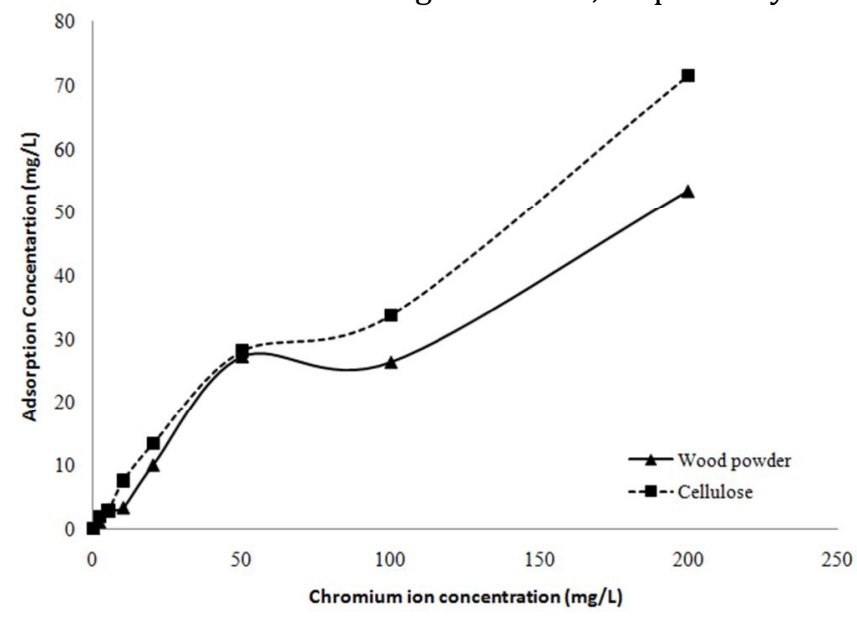

Fig. 4. Effect concentration of chromium ion on adsoption using cellulose and wood powder. 




Fig. 5. Desorption of chromium ion using various reagents (a) on wood powder (b) on cellulose.

Sodium-EDTA can desorb chromium ion into both wood powder and cellulose. On the other hand, ammonium acetate also give significant results in the desorption of chromium ion from wood powder. This results can be accepted due to various active sites involve in the adsorption. Na-EDTA reagent as known well for complexation and the data is indicated the complexation between chromium ion with active site in wood powder and cellulose. Although the data from variation of concentration in Fig. 4 is did not agree with the data in Fig. (5a) and (5b) but the chemical interactions look dominant in this adsorption process. Thus conclude that the adsorption of chromium ion onto wood powder and cellulose are chemical interactions in adsorption system.

\section{Conclusions}

Cellulose from wood powder and raw wood powder as a control can be used as adsorbent of chromium ion. Adsorption of chromium ion onto cellulose and wood powder has rate adsorption constant 0.007 menit $^{-1}$ and 0.002 menit $^{-1}$, respectively. Adsorption capacity for chromium ion onto cellulose is higher than to wood powder, which is $76.92 \mathrm{~mol} / \mathrm{g}$ for cellulose and 55.56 $\mathrm{mol} / \mathrm{g}$ for wood powder. Sodium EDTA, ammonium acetate, hydrochloric acid, and water were applied as desorption reagent to desorp chromium ion from cellulose. The Sodium EDTA is better desorption reagents in order to desorp chromium ion from cellulose and wood powder.

\section{Acknowledgment}

We thank to "Direktorat Jenderal Pendidikan Tinggi"
Republic of Indonesia through "Desentralisasi Program Skim Hibah Fundamental No.1108.a/UN9.4.2/LK-ULP/2013 in fiscal year 2012/2013" for financial support of this research and also to Department of Chemistry, Faculty Mathematic and Natural Sciences, Universitas Sriwijaya for laboratory equipment and facilities. Special thank to Arison Musri for adsorption measurement.

\section{References}

[1] Shriver A., (2006). Inorganic Chemistry, 4th Ed, Oxford University Press, Chichester, ISBN: 1429218207, pp: 434.

[2] Cox.P.A., (2004). Inorganic Chemistry, 2nd Ed, Bios Scientific Publishers, London, ISBN-13: 978-1859962893, pp. 215.

[3] Nachtigall. P, Delgado. M.R, Nachtigallova. D, and Arean. C.0, (2012). The nature of cationic Adsorption Sites in Alkaline Zeolites-Single, Dual and Multiple Cation Sites, PHYSICAL CHEMISTRY CHEMICAL PHYSICS, 14: 1552-1569.

[4] Gupta. S.S, and Bhattacharyya. K.G, (2012). Adsorption of Heavy Metals on Kaolinite and Montmorillonite: A Review, PHYSICAL CHEMISTRY CHEMICAL PHYSICS, 14: 6698-6723.

[5] Walcarius. A, and Mercier. L, (2010). Mesoporous Organosilica Adsorbents: Nanoengineered Materials For Removal of Organic and Inorganic Pollutants, JOURNAL MATERIAL CHEMISTRY, 20:4478-4511.

[6] Lesbani. A, Narsito, and Santosa. S.J, (200). Adsorption Desorption of Zinc(II) on Chitin and Chitosan, MAJALAH SRIWIJAYA, 35:1-6.

[7] Lesbani. A, and Yusuf. S, (2003). Interaction of Copper(II) and Cadmium(II) on Peat From Indralaya South Sumatera, JURNAL ILMIAH MIPA, 6: 49-52.

[8] Risfidian M. Nurlisa H., Ivan W., (2008). Adsorption Study of $\mathrm{Cu}(\mathrm{II}), \mathrm{Cd}(\mathrm{II})$, and $\mathrm{Cr}(\mathrm{VI})$ on Humin From Peat Soil. Proceedings of the International Seminar on Chemistry, Jatinangor, 2008, pp:117.

[9] Chen. X.H, Gosset. T, and Thévenot. D.R., (1990). Batch Copper Ion Binding and Exchange Properties of Peat, WATER RESEARCH, 24: 1463-1471.

[10] Low. K.S, Lee. C.K, and Mak. S.M., (2004). Sorption of Copper and Lead by Citric Acid Modified Wood, WOOD SCIENCE TECHNOLOGY, 38: 629-640

[11] O'Connell. D.W, Birkinshaw. C, and O’Dwyer. T.F., (2008). Heavy Metal Adsorbents Prepared From The Modification of Cellulose: A Review, BIORESOURCE TECHNOLOGY, 99:6709-6724.

[12] Mark. J.E., (2007). Physical Properties of Polymers Handbook, 2nd Ed, Springer, USA, ISBN 978-0-387-69002-5, pp:611-618.

[13] Stuart. B.H., (2004). Infrared Spectroscopy: Fundamentals and Applications, John Wiley \& Sons, Ltd, Chichester, ISBN: 978-0-470-85428-0, pp. 167-183.

[14] Santosa. S.J., Narsito, and Lesbani. A., (2003). The Determination of Active site, Capacity, Energy and Rate Constant on the Adsorption of $\mathrm{Zn}(\mathrm{II})$ and $\mathrm{Cd}(\mathrm{II})$ on Chitin, JOURNAL OF ION EXCHANGE, 14: 89-92.

[15] Masel. R.I., (1996). Principles of Adsorption and Reaction on Solid Surfaces, John Wiley \& Sons, Inc, USA, ISBN-13: 978-0471303923, pp. 240-244.

[16] O'Connell. D.W, Birkinshaw. C, and O'Dwyer. T.F., (2006). A Chelating Cellulose Adsorbent For the Removal of $\mathrm{Cu}(\mathrm{II})$ From Aqueous Solutions, JOURNAL APPLIED POLYMER SCIENCE, 99:888-2897.

[17] Lesbani. A., (2001). The Role of Cationic Exchange and Complex Formation on Adsorption Using Portunus pelagicus Linn as Adsorbent, Master thesis, Gadjah Mada University. 